\title{
Por um chamado ao selvagem em a maçã no Escuro, de Clarice Lispector, e a crítica de Evando Nascimento
}

\author{
For a call to the wild in a maçã no escuro, by Clarice Lispector, and the \\ critical of Evando Nascimento
}

Fabrício Lemos da COSTA*

Universidade Federal do Pará (UFPA)

\begin{abstract}
RESUMO: Este artigo tem como objetivo refletir sobre a presença de um chamado ao selvagem no romance A maçã no escuro (1961), de Clarice Lispector (1920-1977). Assim, recorremos aos estudos críticos de Evando Nascimento, evidenciando a sua abordagem, cujas questões colocamse na clave das novas contribuições interpretativas da ficção clariciana. Neste trabalho, revisitaremos os pressupostos do crítico, presente em seus estudosmais filosóficos até chegarmos às reflexões que abarcam a produção de Lispector. Enfatizaremos, desse modo, como a narrativa pode significar um convite à alteridade, ao pensamento e ao selvagem, no qual Martim, personagem do romance, está imbuído.
\end{abstract}

Palavras-chave: A maçã no escuro, Clarice Lispector, Evando Nascimento, Chamado, Selvagem.

\begin{abstract}
This article aims to reflect about the presence of a call to the wild in the novel $A$ maçã no escuro (1961), by Clarice Lispector (1920-1977). Thus, we appeal to the critical studies of Evando Nascimento, evidencing his approach, whose questions are placed in the key of the new interpretative contributions of Claricean fiction. In this work, we will revisit the critic's assumptions, present in his most philosophical studies, until we reach the reflections that embrace
\end{abstract}

\footnotetext{
* Possui graduação em Letras-Língua Portuguesa pela Universidade Federal do Pará (2012) e Especialização em Produção de Material Didático e Formação de Mediadores de Leitura para EJA pela Universidade Federal do Amapá (2016). Mestre em Letras- Estudos Literários pela Universidade Federal do Pará. Atualmente, é doutorando em Estudos Literários (PPGL/UFPA, 2021). Tem experiência na área de Letras, com ênfase em Literatura Brasileira. E-mail: fabricio.lemos1987@yahoo.com.br
} 
Lispector's production. We will emphasize, in this way, how the narrative can mean an invitation to otherness, thought and the savage, in which Martim, a character of the novel, is imbued.

Keywords: A maçã no escuro, Clarice Lispector, Evando Nascimento, Called, Wild.

"O que este animalé, o que ele terá sido, o que ele seria, quereria ou poderia ser, talvez eu o seja" (Jacques Derrida, $O$ animal que logo sou ${ }^{1}$ )

"Guiava-o a suavidade dos brutos, a mesma que faz com que um bicho ande bonito"

(Clarice Lispector, A maçã no escuro ${ }^{2}$ )

\section{O PULO DE MARTIM: NO DIA EM QUE SE PERDEU, APRENDEU A ANDAR}

O romance A maçã no escuro, de Clarice Lispector, foi publicado pela primeira vez em 1961, pela Editora Francisco Alves. A narrativa tem como personagem central o "herói” Martim, o qual se envolve num verdadeiro itinerário de fuga, após cometer um ato de violência contra a esposa. Com isto, o homem foge, indo parar em uma espécie de hotel fora de rota e quase abandonado.

Neste lugar, ele descansa, mas desconfiado do dono, o Alemão, continua a sua fuga, "pulando", desta vez, para uma espécie de terreno terciário. No entanto, sempre em movimento, o sujeito se depara com uma fazenda, passando a trabalhar com serviços gerais para Vitória, dona do pequeno sítio. Nele, também vive Ermelinda, prima viúva da primeira, e empregados. O romance é divido em três partes: "Como se faz um homem", "Nascimento do herói” e "A maçã no escuro". Vejamos um trecho que demonstra este momento inicial, o da fuga:

Esta história começa numa noite de março tão escura quantoé a noite enquanto se dorme. O modo como, tranquilo, o tempo decorria era a lua altíssima passando pelo céu. Até que mais profundamente tarde também a lua desapareceu.

\footnotetext{
${ }^{1}$ DERRIDA, 2002, p. 63.
}

${ }^{2}$ LISPECTOR, 1961, p. 24.

Revista Moara, n. 59, ago-dez 2021 ISSN: 0104-0944 
Nada agora diferenciava o sono de Martim do lento jardim sem lua: quando um homem dormia tão no fundo passa va a não ser mais do que aquela árvore de pé ou o pulo do sapo no escuro.

Algumas árvores haviam a li crescido com enraizado vagar a té atingir o alto das próprias copas e o limite de seu destino. Outras haviam saído da terra em bruscos tufos. (LISPECTOR, 1961,p. 11, grifo nosso)

Nossa proposta é evidenciar a particularidade que "joga" Martim, por meio de um pulo, para novas possibilidades ao movimentar-se em um "terreno terciário" e antigo. Perguntamo-nos, como fica evidente no fragmento anterior, qual o limite do destino para Martim? O que ele encontrou, vivenciou e experimentou ao longo do seu itinerário, ou ainda, é possível afirmar um Martim antes e após este "pulo" ao ambiente primário? São as perguntas que tentaremos responder ao longo de nosso estudo. Vejamos mais uma passagem, agora, que mostra o "pulo" de Martim:

\footnotetext{
Num pulo macio, que fez o jardim asfixiar-se em suspiro retido, ele se achou em pleno centro de um canteiro - que se arrepiou todo e depois se fechou. Com o corpo advertido o homem esperou que a mensagem de seu pulo fosse transmitida de secreto em secreto eco a té se transformar em longínquo silêncio; seu baque terminou se espraiando nas encostas de alguma montanha. Nin guém ensinara ao homem essa conivência com que se passa de noite, mas o corpo sabe.(LISPECTOR, 1961,p. 17)
}

"O corpo sabe". Temos, aqui, uma chave importante para nossa leitura. O corpo de Martim ao avançar terreno adentro, passa a fazer parte daquele primário lugar. Para isto, por um período, deixa de falar para grunhir, comunicando-se em uma nova linguagem, com toda espécie de vida que ali habita. Martim se mistura à terra, experimenta-a. Além disso, ao vivenciar aquela experiência, um novo homem vai se construindo - desconstruindo-se.

Acreditamos, portanto, que, neste avançar do corpo em canteiro "primitivo", o fugitivo passa a aproximar-se da verdadeira liberdade, aquela distante das burocracias e dos "aprisionamentos" sociais: "Era nisso pois que dava a liberdade. Seu corpo grunhiu com prazer, o termo de lã lhe dava prurid os no calor" (LISPECTOR, 1961, p. 27). É com 
este novo estado, segund o o qual se configura por um contato mais íntimo com a natureza, que iremos desenvolver nossa interpretação.

Nesta primeira seção, iniciamos tratando do "pulo" de Martim, no qual acreditamos estar imbuído o intento da romancista em fazê-lo perder para ganhar ${ }^{3}$. No fundo, com o pulo, Martim começa a andar sozinho. Todavia, esta "perda", de acordo com a nossa leitura pelo selvagem, não se reveste de particularidade ontológica ou místico-religiosa, como é possível verificar em interpretações de cunho existencialista do romance. Dessas leituras, podemos dizer que o Ser é sempre o centro das questões. Benedito Nunes, por exemplo, utilizando um instrumental teórico-filosófico, como Heidegger, Wittgenstein, Sartre, Camus, sublinhou esse caráter ontológico na obra lispectoriana. Segundo Nunes, “a novelística dessa extraordinária escritora pode ser considerada como a mais autêntica e vigorosa expressão da literatura existencial entre nós" (NUNES, 1966, p. 43).

Em nossa abordagem, no entanto, sob o prisma do selvagem e da animalidade, Martim ganha uma espécie de liberdade que o retira da ontologia, da pessoalidade, ou ainda, de um pensamento que vê o sujeito como íntegro, inteiro e total. Então, a experiência do herói que se desconstrói, participa de um "movimento" que marca a crise do romance na modernidade. Queremos dizer, com isto, que esta crise envolve, sobretudo o sujeito, personagem de romance, que, não podendo imaginar-se "absoluto", na maneira como entendíamos o homem da época Renascentista, relativiza o indivíduo e o mundo, como pontua Anatol Rosenfeld (2009) em "Reflexão sobre o Romance Moderno". Para ele:

Também neste tipo de romances se verifica o abandono completo da psicologia "retratista" do romance tradicional. [...] O indivíduo dissolve-se na polifonia de vastos afrescos que tendem a abandonar por inteiro a ilusão óptica da perspectiva, já em si destruída pela simultaneidade dos acontecimentos, a qual substitui a cronologia. Poder-se-ia falar de um enfocação telescópica, de

\footnotetext{
3 Na passagem "aquele que perde a sua vida, ganha a sua vida" (LISPECTOR, 1961, p. 152), acreditamos estar a chave da interpretação do romance. A autora, utilizando-se de um componente cultural, aquele bíblico, visto, por exemplo, na máxima "O que perder a sua alma por mim, acha-la-á" (MATEUS, X, 39), expandiu significativamente aquela "perda" de Martim, da sua vida de outrora, para pensar o lugar do homem diante do animal. Com este, inaugura-se uma discussão ma is a mpla, da ordem do político, em que podemos vislumbrar uma possívelética para todos os viventes, a ssim como pensarmos outras possibilidades de vivência para os homens, ligando-os à vida em sua plena "la tência", isto é, em um orgânico que dispensa burocracias e "liberdades" falsas, porque estão sempre socia lmente vigiados.
} 
grande distância, cujo efeito é o mesmo da microscópica — o "achatamento" do objeto - se o foco não se dissolvesse junto com as personagens visadas, neste mundo imenso da realidade social que sufoca o "elemento" humano. (ROSENFELD, 2009, p. 95-96)

Dessa forma, a vivência de Martim comunga desse desinteresse pela "perspectiva retratista”, de que trata Rosenfeld em relação à modernidade do romance. Neste bojo, é o indivíduo que passa a ser evidenciado em "microscópica" abordagem. No que tange ao herói lispectoriano, o mergulho no Eu inaugura "apelos" e "encontros" com um Outro, o selvagem, no qual, em "chamados", prefigura também a descoberta da animalidade no primeiro, como sublinha, na esteira do pensamento de Jacques Derrida, Maria Esther Maciel em "Poéticas do Animal": "os homens precisam se aceitar como animais para se tornarem humanos" (MACIEL, 2011, p. 98). Desse modo, ao avançar em um terreno antigo, Martim inaugura uma nova maneira de "and ar".

Para isto, o herói experimenta de um "mal"4, metaforicamente inserido como oportunidade de vislumbrar, como uma árvore exposta ao tempo tempestuoso, a sua própria resistência, fortificando-se, muitas vezes, de uma certa "violência", vista no corpo e no seu modo bruto, por exemplo, quando com "voracidade ele todo tentou se tornar apenas orgânico" (LISPECTOR, 1961, p. 50). Em síntese, pelo "mal”, ele buscava maneiras novas e favoráveis para caminhar, em força e voracidade.

Na caminhada, após o pulo, é o animal que desperta no homem qualquer coisa de "estranha" novidade, ou seja, de outras possiblidades de "olhar" para o Natural, muitas vezes, recusando o pensamento lógico e cartesiano. Por outro lado, não temos o intento, neste trabalho, de problematizar o estranhamento como questão que corrobora a possibilidade de um "psicologizante" contato homem-animal.

Neste movimento, os animais, como explica Maciel, "fascinam-nos ao mesmo tempo em que nos assombram e desafiam nossa razão" (MACIEL, 2011, p. 85). Ora, é justamente em "assombramento" que Martim, em grande medida, abandona seus antigos modos, para ir mais longe, provocando o "lado animal que trazemos dentro de nós"

\footnotetext{
${ }^{4}$ Cf. NIETZSCHE, 2009, p. 69: "O mal. — Examinem a vida dos melhores e mais fecundos homens e povos e perguntem a si mesmos se uma árvore que deve crescer orgulhosamente no ar poderia dispensar o mau tempo e os temporais; se o desfa vor e a resistência externa, se alguma espécie de ódio, ciúme, teimosia, suspeita, dureza, a va reza e violência não faz parte das circunstâncias favoráveis sem as quais não é possível um grande crescimento, mesmo na virtude? O veneno que faz morrer a natureza frá gil é um fortificante para o forte - e ele nem chama de veneno."
} 
(MACIEL, 2011, p. 85). No fundo, o sujeito consegue ir "mais longe", porque aceita o apelo selvagem, respondendo em grunhidos, não para se tornar realmente animal, como em simples metamorfose, mas participar, em devir ${ }^{5}$, de uma comunicação de outra “ordem”. Este apelo, no entanto, não tem valor classificatório, ao contrário, dá-se como vida latente que desclassifica para questionar um "logos" antropocêntrico, já que este "diminui”" os animais, vendo-os como pobres de experiência no mundo.

Em suma, Martim é um herói que se desconstrói ${ }^{6}$ ao penetrar e tocar uma maçã no escuro, numa "zona abissal" que rejeita ordem e separação. Estamos, pois, no terreno da alteridade e da nunca definição.

\section{LEITURAS DE EVANDO NASCIMENTO: PENSAR O SELVAGEM}

Abrimos o nosso artigo com uma epígrafe do pensador francês Jacques Derrida. Como sabemos, Evando Nascimento em sua trajetória acadêmica ${ }^{7}$, estudou e publicou vários trabalhos sobre o pensamento desse importante intelectual, natural da Argélia. Sua tese de doutorado, intitulada Derrida e a Literatura: "notas" de literatura e filosofia nos textos da desconstrução, representa o seu maior fôlego nesta pesquisa. No presente estudo, Nascimento formula uma questão fundamental, em que afirma o "motivo" da aproximação entre Derrida e determinados autores da literatura. Esta aproximação justifica-se pelo viés daquilo que ele chama de "literatura pensante". Por sua vez,

\footnotetext{
${ }^{5}$ Cf. DELEUZE; GUATTARI, 1980,p. 291: "Os devires-animais não são sonhos nem fanta smas. Eles são reais. Mas de qual realidade se trata? Pois o devir animal não consiste em tornar-se animal ou imitá-lo" (Tradução nossa).

${ }^{6}$ Utilizamos "desconstruir", aqui, em conformidade com o pensamento de Derrida. Cf. NASCIMENTO, 2004,p. 31: "A desconstrução é um processo geral da própria cultura ocidentale mundial, e tem a ver com a possibilidade do advento do outro e da diferença no discurso metafísico, o qual gostaria de se dar como uno e idêntico a si mesmo. Nesse sentido, ela diz respeito a recalques históricos que resultaram no etnocentrismo da cultura europeia, em relação ao qualo texto platônico seria a té certo ponto sintomático." ${ }^{7}$ Cf. DELMASCHIO; CEI, 2017,p. 72-73: "Um dos mais prolíficos e atuantes pesquisadores e escritores bra sileiros da atua lida de, Evando Nascimentoé autor de diversos livros: de ficção, de crítica literária, sobre artes plásticas e filosofia. [...] Ao longo de sua carreira, vem desenvolvendo projetos que envolvem a Filosofia, a Literatura e as Artes Plásticas. Doutor pela Universidade Federal do Rio de Janeiro, na década de 1990 foi aluno de Jacques Derrida, na École des Hautes Études en Sciences Sociales, de Paris. [...] Realizou um Pós-Doutorado em Berlim. [...] No Brasil é um dos maiores especialistas no domínio do pensamento francês recente. Em 2004, organizou o 'Colóquio Internacional Jacques Derrida', em que o filósofo franco-argelino fez a conferência de abertura. [...] Destacam-se na sua produção teórico-crítica: Derrida e a literatura (EduFF, 1999), Ângulos: literatura e outras artes (Argos, 2002); Derrida (Zahar, 2004); Pensar a Desconstrução (Estação Liberdade, 2005); Clarice Lispector: uma Literatura Pensante (Civilização Bra sileira, 2012)."
} 
consideramos esta particularidade a clave do interesse de Nascimento pela ficção de Clarice Lispector. Em relação às preferências de Derrida, ele sublinha:

No plano da literatura, a preferência de Derrida se faz porautores como Celan, Ponge, Shakespeare, Joyce, Poe, Baudelaire, Genet, Kafka, Jabès... uma série em que Mallarmé não é certamente o menor deles. A escolha se justifica pelo tipo especial de literatura que praticaram: chamaria, por antecipação, uma literatura pensante.(NASCIMENTO, 1999, p. 22, grifo do autor)

Dialogando com Derrida, Nascimento realiza a sua interpretação da produção ficcional lispectoriana. $\mathrm{Na}$ oportunidade de estimular o pensamento pela literatura, o crítico desenvolve uma diversidade de temáticas a partir da obra dessa escritora. Em suma, sob a "roupagem" do "pensar", evidenciado nos romances, contos e crônicas, o estudioso elabora seus argumentos em tópicas, como o "Inumano", a "Ferocidade", o "Mal", entre muitas outras. Escolhemos estas como exemplo, porque de alguma forma dialogam com o pressuposto de que na literatura de Clarice Lispector, temos a presença, vocação ou chamado para o selvagem e o animal. Segundo Nascimento:

Existe em Clarice uma nostalgia de não ter nascido e crescido bicho de todo [...] Isso se configura no chamado, o apelo ou a vocação (em sentido etimológico: uma questão e voz, chamamento, intimação e convite) que sente vindo dos bichos. Ao colocar sua temática a nimal na perspectiva do chamado, Clarice traz de volta certo recalque fundante de nossos valores culturais. (NASCIMENTO, 2012,p. 27)

Vê-se que a crítica de Nascimento inaugura novas perspectivas de leituras em romances como A maçã no escuro, por exemplo. Dada a sua inclinação para estudos derridianos, o pesquisador lê a ficção de nossa ilustre romancista pelo viés de projetos implicados em sua formação universitária. Sobre o interesse em Clarice Lispector e a interlocução com outras reflexões de ordem acadêmica, ele declara:

Clarice Lispector entrou em minha vida muito cedo, no momento em que ingressa va na universidade, e desde então a interlocução nunca se interrompeu. Em inúmeros momentos da formação e da vida profissional, detive-me no corpus dessa obra, em que seu corpo digamos $i$-material, para dele extrair 
projetos, indagações e sobretudo ensaios, que constituem parte importante de minha produção escritural. (NASCIMENTO, 2012,p. 7)

Destarte, a reflexão crítica sobre a obra clariciana, realizada, sobretudo no livro Clarice Lispector: uma literatura pensante, publicado em 2012, pela Editora Civilização Brasileira, é importante para pensarmos a "atualização" interpretativa na recepção ficcional dessa autora. Vemos prefigurar, neste trabalho de Nascimento, uma ênfase por temáticas muito caras aos seus estudos e projetos, principalmente em torno do pensamento de Derrida, como dissemos.

Partindo-se dessa premissa, escolhemos o chamado ou vocação ao selvagem, como uma das tópicas que se realiza com maior fecundidade no romance, corpus de nossa reflexão. Assim, para além das leituras existencialistas, já abordadas por críticos, como Benedito Nunes ${ }^{8}$, Nascimento alarga a interpretação em torno da literatura de Lispector, oferecendo-nos novas maneiras de ler as narrativas, como se dá na discussão da aproximação entre o homem e o animal, momento de contato por um chamado, cujo movimento leva o homem a uma radical alteridade.

Dessa maneira, a presença da animalidade em A maçã no escuro traz à tona certos recalques, isto é, modos de ser e agir que ficam escondidos no interior de cada homem. O recalque em questão, assim, subjaz quando do contato de Martim com o orgânico. Sozinho, em pleno "Coração do Brasil”, o sujeito manifesta em si o que estivera sempre contido, para, enfim, "explodir" em plena aproximação com os outros inumanos, potencializando, então, o animal que nos habita. Por vezes, como sabemos, o escondido revela também o "imundo", "a sujeira", "o informe" e tudo aquilo que é reprimido e socialmente afastado.

Com esta abordagem, consideramos que a crítica de Nascimento deve ser entendida como uma das leituras mais recentes na história da recepção crítica de Clarice Lispector. Em primeiro lugar, a interpretação pode ser justificada pelo instrumental teórico que utiliza, como Jacques Derrida, que já mencionamos, e Georges Bataille, outro importante pensador francês. Em segundo lugar, o estudioso articula suas reflexões mais "filosóficas" com a literatura, de modo que nenhuma sai em prejuízo, em detrimento da outra. Antes, elas se imbricam como manifestação mais pura do pensamento, em que a

\footnotetext{
${ }^{8}$ Entre os trabalhos mais importantes desse crítico, podemos citar os seguintes livros: $O$ mundo de Clarice Lispector (1966), Leitura de Clarice Lispector (1973) e O drama da linguagem: uma leitura de Clarice Lispector (1995).
} 
última, mesmo não tendo como objetivo a ordenação conceitual, como é próprio da filosofia, consegue desenvolver, no ato da leitura, o pensamento por meio de sua constituição estético-reflexiva.

Como sublinha o autor, não estamos falando de uma visão psicanalítica dessa literatura, mas em oportunidade de pensar a alteridade como questão atual, que, envolve, sobretudo, outros viventes: "Não se trata aqui de psicanalisar as relações entre homens e bichos segundo Clarice, mas de compreender como certo 'estranho familiar' perpassa a visão dessa nossa alteridade" (NASCIMENTO, 2012, p. 25). Nosso objetivo é observar como este inumano se desenvolve esteticamente no romance A maçã no escuro, visto sob a perspectiva da interpretação de Nascimento. Vale ressaltar que a aproximação entre homem e animal, no plano da ficção, é uma temática abordada por muitos estudiosos na atualidade, principalmente com o advento das discussões que envolvem a biopolítica, como se verifica, por exemplo, nas pesquisas de Maria Esther Maciel, em que ressalta a questão da "animalidade" como encontro que "desafia a nossa capacidade de circunscrevê-lo em categorias do pensamento" (MACIEL, 2011, p. 88).

Na crítica sobre a ficção de Clarice Lispector, Evand o Nascimento é responsável por fomentar essas discussões, como é possível encontrar em várias de suas entrevistas, em que assume estar a autora presente desde o início de seu percurso acadêmico, no qual a lê, em grande medida, no encontro com o seu outro interesse de pesquisa, o pensamento de Jacques Derrida.

Em um breve texto intitulado "Eis a defesa da solidariedade dos viventes", publicado no Suplemento Cultural de Pernambuco, Nascimento (2017, p. 23) explica que o pensamento de Derrida, influenciou, por exemplo, intelectuais brasileiros como Haroldo de Campos, que, ao publicar O Sequestro do Barroco, em 1983, insere no plano da reflexão crítica brasileira as ideias do autor de $A$ Escritura e a Diferença. Recentemente, em 2017, também Silviano Santiago, segundo Nascimento, volta-se a Derrida em Genealogia da Ferocidade, que tem Grande sertão: veredas (1956), de Guimarães Rosa, o objeto de análise. Vê-se, então, como Derrida continua presente na reflexão de vários estudiosos no cenário da crítica brasileira.

Tendo como base o argumento de Nascimento, acreditamos que este, como estudioso e aluno de Derrida, também se encontra neste rol de ensaístas brasileiros que incorporaram as questões derridianas em suas críticas. No caso de Nascimento, é a ficção 
de Lispector o seu maior interesse. Para isto, desenvolve o "pensamento" como clave das suas reflexões. Em entrevista de 2017, ele revela que quando inventou a categoria de "literatura pensante", por volta de 1992, base de sua tese Derrida e a Literatura, "tinha em mente autores e autoras que faziam um tipo de literatura muito próxima do ensaio" (NASCIMENTO, 2017, p. 75). Portanto, essa particularidade "pensante", como demonstra o próprio crítico, imbrica-se no seu percurso acadêmico e intelectual, sendo também fundante na interpretação da ficção lispectoriana.

Em relação ao pensador francês, ele acrescenta: "as referências filosóficas de Derrida e de outros pensadores entram como algo que faz parte de meu trajeto, jamais como 'teses' ou 'conceitos'. Tenho horror a literatura filosófica, que acho entediante" (NASCIMENTO, 2017, p. 75). Dessa forma, utilizando-se do pensamento de Derrida, não como "conceito", característica que seria do filosófico, é que devemos compreender as referências derridianas na leitura de Lispector. Nunca para desenvolver uma "tese", como se estivesse em "jogo" qualquer tentativa de justificar uma "questão" filosófica em Clarice. Ao contrário, pelo pensamento, a obra se deixa "falar". Vejamos ainda o que ele explica sobre o diálogo com Derrida:

O legado de Derrida é imenso e promete se desdobrarnos séculos vindouros. Desde o início, ele estabeleceu um diálogo com a literatura. Daí ter inventado e desenvolvido em minha tese de doutorado a categoria "uma literatura pensante", para abordaras relações entre literatura e filosofia. De maneira resumida, a literatura proporia um tipo de pensamento, distinto do filosófico. [...] O melhor exemplo disso é a questão da animalidade, que somente no século XXI ganhou plena relevância filosófica, e não poracaso foio tema dos últimos seminários de Derrida. Uma escrita como a de Clarice Lispector é pensante justamente por ficcionalizar com grande sensibilidade ética os animais. Não há mais, na ficção clariciana, uma oposição simples entre Homem, de um lado, e os animais, do outro. Trata-se de pensar também a a nima lida de dos humanos e a "ra cionalida de" animal, com sua lógica vital toda própria. Cães, macacos, ga linhas e coelhos, entre outros bichos, povoam esse ima ginário aberto à alterida de. (NASCIMENTO, 2017,p. 23)

Com a longa citação anterior, passaremos a tratar, mais de perto, o caso de Martim, embora já tenhamos feito, no início de nosso estudo, um breve apanhado do motivo da 
fuga à oportunidade de um "ganho", visto como da "ordem" do pensamento, da alteridade e da liberdade.

\section{MARTIM E O APELO SELVAGEM}

Martim, no "Coração do Brasil", experimenta um chamado da natureza, e, nesta invocação, inicia seu contato pelas vias do selvagem. Obviamente, o fugitivo, antes de adentrar no terreno antigo e primário, não sabia o que encontraria, entretanto, como em fascínio que advém da animalidade, aceita o "convite", e, neste ato, tem a oportunidade de encontrar-se como humano, segundo novas possibilidades. Dessa forma, concordamos com Maciel quando diz que "os humanos precisam se reconhecer animais para se tornar humanos" (MACIEL, 2011, p. 87). Com esta afirmação, ressaltamos que neste "Coração do Brasil", visto como lugar antigo e primário, Martim não tem objetivo de tornar-se animal, antes, este último pode ser o elo da animalidade perdida ou escondida naquele homem.

Com isto, busca-se, metaforicamente, um contato com uma espécie de "grau zero" do estado natural, movimento que só é possível caso seja atendido ao apelo selvagem, que o retira de todo pensamento totalizador e acabado. Para este intento, entretanto, é mister romper com uma separação entre homem e animal, ou seja, com a invenção cartesiana. Esta, tinha como fim nos distinguir como criaturas supostamente "pensantes", diferentes dos animais, vistos apenas como uma coisa, por vezes, uma "máquina" ou "objeto".

Ao romper com um lógos ocidental, Martim prefigura a possibilidade da mudança em si mesmo. Com isto, instala-se, na força de uma literatura pensante, a desconstrução. Nascimento, faz lembrar, no entanto, com base no pensamento de Derrida, que "as desconstruções são um processo que existe desde sempre e que se refere a mudanças radicais no plano das civilizações" (NASCIMENTO, 2017, p. 22). Queremos dizer, conforme a reflexão do ensaísta, que, Martim participa desse desejo de modificação interna, com base, principalmente, no "olhar" do bicho.

Poder-se-ia falar, portanto, em "desconstrução do humanismo tradicional" (NASCIMENTO, 2017, p. 22), no qual a "cisão" pede, por vezes, a desclassificação. Desse modo, pela vivência com o inumano, o fugitivo se transforma, e nesta mudança, resgata a discussão sobre um mundo da animalidade para questionar um certo 
"falocentrismo" do homem burocrático e radical. Destarte, entendemos o silêncio, ou seja, o "corte" da voz, no sentido de ruptura com a comunicação verbal, em vários momentos do romance, como marca fundamental deste movimento, que, ao calar e caminhar em terreno antigo, é contagiado pelos Outros.

$\mathrm{Na}$ primeira parte da narrativa, podemos constatar a indicação desse chamado animal. Um indício interessante desse envolvimento com o inumano, pode ser percebido na passagem em que Martim esquece o motivo da fuga, tamanha é a ligação que começa a se instalar entre ele e o selvagem: "Qualquer porém que tivesse sido o motivo, esquecera-o. E andando sem parar, o homem coçou violentamente a cabeça com duros dedos: tinha um gosto danado de ter esquecido." (LISPECTOR, 1961, p. 23-24). Martim, no esquecimento, ao mesmo tempo, prefigura qualquer coisa de primitivo modo de ser e agir, como faz lembrar a dureza dos dedos e a violência em que coça a cabeça. Ele, afinal, queria apenas existir, como um bicho, vivendo sem projeções para o futuro, lógicas de projetos e burocracias: "aquele homem procurava se manter apenas vivo, e nada mais assim como o animal brilha apenas nos olhos, mantendo atrás de si a vasta alma intocada de um animal" (LISPECTOR, 1961, p. 33).

Neste bojo, Martim, ao deixar de ser homem preso aos condicionamentos sociais, morais e burocráticos, passa a comunicar-se quase sem linguagem humana. Aos poucos, o fugitivo responde por grunhidos, próprio da animalidade: "aquele homem rejeitara a linguagem dos outros e não tinha sequer começo de linguagem própria. E no entanto, oco, mudo, rejubilava-se. A coisa estava ótima" (LISPECTOR, 1961, p. 36). No rompimento com o socialmente estabelecido, Martim encontra uma maneira nova de ser, desprendendo-se da linguagem verbal para se libertar e sentir-se à vontade: "agora que Martim perdera a linguagem, como se tivesse perdido o dinheiro, seria obrigado a manufaturar aquilo que ele quisesse possuir [...] aquele homem acabara de se desprender definitivamente" (LISPECTOR, 1961, p. 42). Portanto, com a perda da linguagem, mesmo que por um tempo, Martim se movimenta neste lugar primário, contemplando a orgânica mistura informe do pequeno mundo primitivo:

Ervas cresciam verticais. Algumas haviam atingido uma altura que já as torna va sensíveis à brisa adstringente da aurora. Outra s era m ra steira s e coladas a o chão, e deste não se arra ncariam sem morte. Terra grossa se esfarela va junto de um formigueiro; era uma desordem tranquila. [...] E se a visibilidade atingia 
o terreno, revelavam-se folhas mortas se decompondo, pardais que se confundiam com o chão como se fossem feitos de terra, as ratas negras e miúdas que haviam feito ninho naquele mundo rudimentar. (LISPECTOR, 1961,p. 89-91)

Ao lado do orgânico, é imprescindível falarmos também na presença do informe, o qual mistura tudo, como os "pardais que se confundiam com o chão". A natureza contemplada por Martim, como mostra o fragmento acima, parece constituir-se no plano da desclassificação. Na presente realidade, formas prefiguradas e fixas são destituídas de valor e sentido, antes, o pequeno mundo primitivo e rudimentar fundamenta-se pela negação das formas acabadas, no qual o homem passa a fazer parte, porque, nele também categorias são invalidadas, perfazendo-se em desconstrução de si. Para isto, vale a pena recorrermos ao verbete "Informe”, presente na Revista Documents, de Georges Bataille:

\footnotetext{
Assim, informe não é a penas um a djetivo que tem este ou aquele sentido, mas um termo que serve para desclassificar, exigindo geralmente que cada coisa tenha sua forma. O que ele designa não tem seus direitos em sentido algum e se faz esmagar em toda parte como uma aranha ou uma minhoca. [...] Em contrapartida, afirmar que o universo não se assemelha a nada e é apenas informe equivale a dizer que o universo é algo como uma aranha ou um escarro.” (BATAILLE, 2018, p. 147, grifo do autor)
}

Em A maçã no escuro, como fica demonstrado em várias passagens, emerge um lugar que transborda a recusa à classificação. Neste ambiente, onde o ancestral e o arcaico imperam, é o espaço também do nascimento de um novo herói, o qual só tem sentido como manifestação da autêntica "deseroização". Dessa maneira, temos, aqui, algumas questões respondidas, como o que Martim encontrara naquele jardim antigo e terciário. Poder-se-ia dizer que encontrou, tête-à-tête com o viventes, apelos para se tornar mais bruto e selvagem. Para isto, é preciso que a comunicação se realize numa nova linguagem, sem palavras e feita em grunhidos.

Então, percebe-se a presença material de um orgânico vivo em A maçã no escuro. Em latência, pulsa vida pelas vias da mistura, fazendo, por exemplo, os pardais se confundirem com o terreno, "como se fossem feitos de terra". Em desorganização orgânica, Martim se movimenta, percorre o ambiente, coloca um pássaro na mão, oferece 
um breve sermão às pedras, cruza montanhas, responde em grunhidos, até chegar à fazenda de Vitória.

Portanto, neste acontecimento, a alteridade e a troca, perfazem-se à céu aberto em expansão. Nessa manifestação, entendemos como o animal e os homens estão imersos numa ancestralidade comum, como nos faz lembrar Evando Nascimento (2013) em seu artigo "Clarice Lispector: les animaux, les choses, la pensée", publicado no livro Clarice Lispector: une pensée en écriture pour notre temps. Partindo-se de um ponto comum, é preciso pensar Martim como parte natural desse ambiente. Ao silenciar, o homem se integra completamente a uma posição ancestral, sempre disponível, isto é, por meio da natureza bruta, recupera-se o animal que lhe habita.

Em A maçã no escuro, dessa forma, vemos o corpo a corpo com a vida, cuja alteridade envolve Martim num silêncio que nasce como necessidade de emudecer para melhor misturar-se ao outro. Neste ínterim, o herói assume ao longo do seu itinerário, uma postura de desligamento com a vida de outrora, para emergir, no plano ficcional, o pensar sobre a posição do animal — o estranho familiar. Sob este aspecto, é possível refletirmos também sobre uma literatura estranha, isto é, fora do lugar no que diz respeito à tradição - a Belles Lettres —, como afirma Nascimento (2013). Em suma, a ficção clariciana expõe uma animalidade diversa em toda a sua produção, fazendo vir à tona o escondido, o guardado, o abafado, o preso, o animal que Martim é:

\footnotetext{
Aquele homem parecia não querer nunca mais usar o pensamento nem para combater outro pensamento - foi fisicamente que de súbito se rebelou em cólera, agora que enfim aprendera o caminho da cólera. Seus músculos se comprimiram selvagemente contra a imunda consciência que se abrira a o redor da unha. Ilógico, lutava primitivamente com o corpo, torcendo-se numa careta de dor e de fome, e com voracidade ele todo tentou se tornarapenas orgânico.
} (LISPECTOR, 1961, p. 50)

"Selvagemente", "primitivamente", "voracidade”, "orgânico": São palavras que ganham enorme destaque neste trecho do romance, comprovando a nossa leitura, segundo a reflexão crítica de Evando Nascimento. Aquele homem, solto, experimentando da liberdade, sabe que é preciso desligar-se do pensamento lógico, para, enfim, aflorar um outro "ilógico", cujo sentido corrobora o apenas viver, sem projetos e "prisões" sociais. 
Portanto, as provocações interpretativas lançadas por Nascimento no que tange aos animais e seus chamados em Clarice, revelam-se fundamentais para pensarmos a saída brusca de Martim em um mundo "indomesticado" e mais selvagem. Este, ao fugir, "instala" a possibilidade do questionamento no que diz respeito aos lugares fixos, categorias, classificações e suas desconstruções, na medida em que nos revela a mistura e o informe.

Sob esta particularidade da ficção de Lispector, voltada para a despersonalização, Regina Machado (1989) afirma: "Tanto para Martim como para G.H., o ponto de partida de uma tal obra de construção é a destruição de toda vida pessoal, e o trabalho de construção supõe a afirmação dessa perda inicial, que aparece como revelação de uma vida maior" (MACHADO, 1989, p. 121). Sublinhamos, aqui, conforme o pensamento de Nascimento, que a "vida maior" pode estar relacionada a este "olhar" para o outro, podendo ter no animal uma oportunidade de voltar ao seus secretos modos selvagens, no fundo, ao escondido. Neste bojo, Martim não deixa de ser homem, mas possibilita a entrada para um novo humanismo, que, em solidariedade, integra-se com os outros viventes.

Desconsiderando um fundo ascético na trajetória de Martim, preferimos compreender a saída desse herói de qualquer certeza, colocando-o no campo da rasura e da não totalidade. Sob este aspecto, temos nas leituras de Nascimento uma chave para inserirmos o "herói” do romance em discussões que movem temas como alteridade, diferença e desontologização pela aproximação com os inumanos. Interessamo-nos, dessa forma, sobretudo por esta experiência de estar apenas vivo e sem projetos, quiçá, sem pensamento e sem lógica, sendo, pois, apenas orgânico:

\footnotetext{
O homem não tinha nenhum plano formado e, como arma, parecia ter apenas o fato de estar vivo. Na tarde ma is tranquila, ele a gora caíra numa clarividência vazia e humildemente intensa que o deixava corpo a corpo com o pulso mais íntimo do desconhecido. Sua vontade continua a vançar. (LISPECTOR, 1961, p. 54)
}

Seguind o o itinerário do fugitivo em seu contato com o animal, destacamos ainda o momento inicial do romance. Na chegada do homem à fazenda, ele passa a trabalhar com serviços diversos, reparando cercas, cuidand o do curral, mesmo sendo engenheiro 
de formação. Não podendo escolher, ele faz de tudo um pouco. Em pleno sítio, depois da experiência com outros viventes inumanos, anterior à fazenda, Martim volta a ser "invocado" ao orgânico, ao bruto e ao latente. Agora, pelas vacas do curral:

\footnotetext{
Num suspiro resignado, pareceu a o homem lento que "não olhar" ta mbém seria o seu único modo de entrar em conta to com os bichos. Imitando as vacas, num mimetismo quase calculado, ele ali em pé não olhou para parte alguma, tentando ele também dispensar a visão direita [...] Depois, por um altruísmo de identificação, foi que ele quase tomou a forma de um dos bichos. E foi assim fazendo que, com certa surpresa, inesperadamente pareceu entender como é uma vaca.(LISPECTOR, 1961,p. 106)
}

Neste momento, como se vê, Martim se aproxima com maior voracidade para o "mundo" dos bichos. No curral, o imundo, a sujeira, o cheiro demasiadamente forte das vacas, colocam-no na mais íntima experiência com o estado bruto da natureza. O herói representa aquele que atende sem limitações ao chamado, isto é, de uma vocação, presente em cada mulher e em cada homem, cujas marcas estão imbuídas nas personagens de Clarice Lispector, como podemos verificar no conto "O búfalo", do livro Laços de Família (1960).

Recebendo e acolhendo o "convite" inumano, é possível ler a capacidade e força do pensamento a partir deste romance, como acredita Nascimento. Assim, em pleno chamado, Martim, ao ser contagiado pelos animais, apela também ao silêncio. Na fazenda, pelo olhar, a vaca o espreita, e, nesta observação, o silêncio continua como parte daquela vivência. Sobre o silêncio que advém dos animais, Jacques Derrida se pergunta sobre si mesmo ao perceber o olhar de seu gato:

Há muito tempo, pode-se dizer que o animal nos olha?

Que a nimal? O outro.

Frequentemente me pergunto, para ver, quem sou eu - e quem sou eu no momento em que, surpreendido do nu, em silêncio, pelo olhar de um animal, por exemplo os olhos de um gato, tenho dificuldade, sim, dificuldade de vencer o incômodo.(DERRIDA, 2002, p. 15, grifo do autor) 
É inegável o valor dado ao silêncio no percurso de Martim. Na recepção existencialista da obra de Clarice, o silêncio foi lido como qualquer coisa de manifestação do divino, ou ainda, como um limite que não pode ser ultrapassado, portanto, não entendido e traduzido. O presente entendimento pode ser compreendido por meio do aforismo de Wittgenstein: "O que não se pode falar, deve-se calar" (WITTGENSTEIN, 1961, p. 129). Por outro lado, conforme o pensamento de Derrida, preferimos interpretar o "calar" clariciano como da ordem do silêncio que ao se instalar na vivência de tantos personagens da autora, prefigura uma oportunidade de alargar uma discussão em torno dos demais viventes, como elabora Nascimento em sua leitura de Lispector.

Neste intento, a comunicação logocêntrica e antropocêntrica desaparece para fazer "falar", pelo olhar, o animal no homem. Em relação ao silêncio posto no devir homem/animal, é importante o que sublinha Maciel. Segundo ela:

\footnotetext{
Pensar, imaginar e escrever o animal só pode ser compreendido como uma experiência que se aloja nos limites da linguagem, lá onde a aproximaçãoentre os mundos humano e não humano se torna viável, apesar de eles não compartilharem um registro comum de signos. (MACIEL, 2011, p. 94, grifo nosso)
}

Portanto, desde o jardim até o curral, Martim abre as comportas da desorganização, do desclassificado, do informe e do infamiliar. De acordo com Nascimento, "o infamiliar, por ser informe, é mais amplo, invadindo desde sempre o espaço do mesmo, do lar" (NASCIMENTO, 2012, p. 224). Como dissemos, no curral, o "infamiliar" se expande em longo tempo de experiência, onde Martim se habitua à imundície: "Uma pessoa pouco corajosa poderia vomitar à fragrância imunda, e ao ver a atração que as moscas tinham por aquela chaga aberta, uma pessoa limpa podia se sentir mal diante da tranquilidade com que as vacas de pé molhavam pesadas o chão" (LISPECTOR, 1961, p. 105). Assim, em muitos momentos, Martim, quase monossilábico para com os outros habitantes do sítio, evade-se para o curral. Lá, ele mantém uma comunicação com o animal, como já tinha vivenciado após a fuga do hotel. Ainda no curral, Martim pertencia todo àquele ambiente: 
E enfim pôde olhá-lo como uma vaca o veria:

O curral era um lugar quente e bom que pulsa va como uma veia grossa. Era à base dessa larga veia que homens e bichos tinham filhos. [...] Era à base de um curralque o tempo é indefinidamente substituído pelo tempo. Era por causa desse latejar que levas migratórias saíam de zonas frias para as temperadas. Aquele - aquele era um lugar quente que pulsava. (LISPECTOR, 1961, p. 108)

Desse modo, os pressupostos evidenciados por Nascimento ao longo de sua crítica, vista desde a sua pesquisa no que tange ao "pensamento em certas literaturas", de acord o com Derrida, expõem novas abordagens na obra da autora, permitindo-nos pensar temas contemporâneos, como a questão de gênero. Entre a diversidade temática trazida à tona para interpretar essa literatura, é evidente que a animalidade e seu chamado, mostrase interessante para problematizarmos a retirada do homem da "máquina antropológica", expressão cunhada por Georges Agamben (2017, p. 55) em O Aberto.

Olga de Sá em Clarice Lispector: a travessia do oposto, revela que tipo de leitor A maçã no escuro "reclama". Segundo ela, o romance "aspira a um leitor de 'fruição'. Que leia tudo, sem pressa" (SÁ, 2004, p. 69). Acrescentamos, partindo do argumento de Sá, que é preciso um leitor que compreenda Lispector para o nosso tempo, "iluminandoa" de questões atuais.

A maçã no escuro, como todas as narrativas de Clarice, apresenta esse teor da novidade, de obra feita para o nosso momento, como comprova os estudos da sua obra, segund o a abordagem biopolítica ${ }^{9}$, por exemplo. A presença ficcional do animal, o seu chamado, em suma, entra nesse rol de atualidade, em que o romance é representativo.

Dialogando com este viés, da presença do orgânico e da latência viva na narrativa, Sá argumenta: "o terreno, onde a natureza se impunha, soberana, pertencia à aurora do mundo, tempo em que a inteligência servia apenas à sobrevivência da espécie, como os ratos [...] Lentamente, o homem prepara-se para o encontro com o reino animal" (SÁ, 2004, p. 77). Vê-se que essa temática, lembrada brevemente por Sá, Nascimento desenvolve como ponto central de sua crítica.

Martim, de formação matemática, desde a fuga, como estamos desenvolvendo neste estudo, aos poucos, abandona o mundo dos números, dos cálculos e projetos,

\footnotetext{
${ }^{9}$ Ver o estudo de Gabriel Giorgi, intitulado Formas Comuns: animalidade, literatura, biopolítica (2016). 
portanto, do logos, para fazer emergir um outro, marcado pela desordem, pelo desclassificado, pelo encontro com o (s) Outro (s), pela alteridade, como a passagem do curral faz lembrar:

\begin{abstract}
Habituado a números, ele recuava à desordem. É que dentro era uma atmosfera de entranhas e um sonho difícil cheio de moscas.E só Deus não tem nojo. No limiar, pois, ele parou sem vontade.

A névoa evolava-se dos bichos e os envolvia lenta. Ele olhou mais no fundo. $\mathrm{Na}$ imundície penumbrosa havia algo de oficina e de concentração como se daquele enleio informe fosse aos poucos se aprontando concreta mais uma forma. O cheiro cru era o de matéria-prima desperdiçada. Ali se faziam vacas. Por nojo, o homem que repentinamente se tornara de novo abstra to como uma unha, quis recuar; enxugou com o dorso da mão a boca seca como um médico diante de sua primeira ferida. No limiar do estábulo no entanto ele pareceu reconhecer a luz mortiça que se exa lava do focinhodos bichos. Aquele homem já vira esse vapor de luz evolando-se de esgotos em certas madrugadas frias. E vira essa luz se emanarde lixo quente. (LISPECTOR, 1961, p. 104)
\end{abstract}

Partindo da longa citação anterior, vemos a presença do animal em plena latência no curral. Nele, o imundo, a desordem, as entranhas, o cru, concretamente, submergem para fora, mostrando ao homem as "feridas abertas" da coisa orgânica. Da desorganização, como se vê, o informe, próprio do imundo, evola-se em cheiros fortes, no qual é preciso esforço para se acostumar, revelando a Martim e aos leitores, que esse "universo não se assemelha a nada", como pensa Bataille (2018, p. 147). Nesta perspectiva, consideramos o selvagem e seus chamados uma maneira interessante de ler o romance $A$ maçã no escuro, sem aprofundar, no entanto, pelas vias de uma questão psicanalítica, no qual tem o "recalque" e o "mal-estar", como sabemos, uma de suas temáticas depesquisa. Tampouco quisemos aprofundar pela ótica antropológica a relação Martim-animal, com seus conceitos e teorias, mesmo sabendo da possibilidade.

Em síntese, é importante destacarmos que a narrativa $A$ maçã no escuro já foi abordada por outra via existencialista e místico-religiosa, imbuída talvez por passagens como esta: "aquele que perde a sua vida, ganha a sua vida" (LISPECTOR, 1961, p. 152). Benedito Nunes (1995) em seu livro O Drama da Linguagem: uma leitura de Clarice Lispector, por exemplo, leu a caminhada de Martim por este viés: 


\begin{abstract}
Martim necessita abdicar de si mesmo — de seu nome e de sua condição para encontrar, absorvido pela rea lida de absoluta que o cerca va e incluía, como fonte remota e escura dele mesmo, a sua verdadeira identidade no total despojamento do Eu. [...] Seria A maçã no escuro, portanto, de acordo com essa linha mística, que até aqui acompanhamos, uma parábola da máxima evangélica segundo a qual aquele que perde a sua vida há de ganhá-la. (NUNES, 1995, p. 44-45)
\end{abstract}

É perceptível, assim, qualquer coisa de evangélica provocação na passagem, de acordo com a recepção de leitura existencial. Todavia, nosso objetivo, aqui, é formular uma interpretação por caminhos que tratam da desontologização de Martim, em que é possível verificar um chamado orgânico e latente. No fundo, dá-se na presença de uma pura matéria pulsante. Nesse sentido, o que o herói ganha é a perda da identidade fixa, para emergir um outro que se mistura com todos os viventes - animais e plantas, sobretudo.

Por fim, muita coisa acontece ao longo do romance. Martim se envolve com Ermelinda, preocupa-se com as visitas do Professor, amigo e espécie de conselheiro de Vitória, fica pensativo com possíveis suspeitas de Vitória sobre o seu passado de fugitivo. Ao final, o homem é preso, e, nesta situação, descobre que a esposa não está morta, pois conseguira sobreviver da violência cometida. Em suma, neste trabalho, destacamos a relação Martim-orgânico-selvagem — o simples viver.

\title{
CONSIDERAÇÕES FINAIS
}

Desde o aparecimento de A maçã no escuro na década de 1960, vários estudiosos têm se dedicado ao exame do romance, compreendendo-o no conjunto temático da obra clariciana. Na mesma década da sua publicação, a narrativa já era interpretada pela ótica daleitura existencialista, como é possível verificar no trabalho de críticos, como Benedito Nunes, por exemplo. Para a recepção existencial, o animal em Lispector ganha "dimensão ontológica”, como pontua Nunes (1966, p. 60). Por outro lado, em nossa abordagem, a animalidade não serve para enfatizar a centralidade do Ser humano, tampouco o seu 
privilégio diante dos inumanos, "os pobres de mundo", como pensa o filósofo Heidegger, o qual é sempre invocado na recepção existencialista.

Sob este prisma, argumentamos que a recepção da ficção da escritora pela crítica especializada mais recente, tem se expandido para novas e atuais leituras, enfatizando temáticas como o lugar do animal e do selvagem nas relações naturais entre homens e estes últimos. Destaca-se, neste viés, o trabalho de Evando Nascimento, o qual desde o início de seus estudos universitários, aproximou-se dos textos de Lispector, lendo-os pela perspectiva do seu interesse de pesquisa, como mostra o seu livro Clarice Lispector: uma literatura pensante, publicado em 2012, pela Civilização Brasileira. Nele, é possível verificar a relevância da categoria "pensante" de certas literaturas.

Neste trabalho, lemos o romance A maçã no escuro pela abordagem desse crítico, cuja reflexão nos estimula a (re) pensar a obra de Clarice, sobretudo naquilo que ela tem de mais atual possível, na medida em que certas temáticas, como o chamado animal, consegue dar conta de diversas discussões pontuais para o nosso tempo. Em síntese, neste estudo, nossa finalidade foi pensar o itinerário de Martim, personagem central da narrativa, inserindo-o na clave de um interesse pela animalidade, quando este se retira de um "mundo" burocrático para melhor contemplar, agir e movimentar-se junto ao terreno primário, antigo, informe e desorganizado. Desligado da lógica, dos números e da organização que pertencia, Martim precisa silenciar, emudecer para melhor conectar-se a este outro lugar: estranho, escondido, indomesticado, "infamiliar, visto, principalmente, no "olhar" dos animais e na mistura com todas as formas de vida.

\section{REFERÊNCIAS}

AGAMBEN, Giorgio. O aberto: o homem e o animal. Trad. Pedro Barbosa Mendes. 2. ed. Rio de Janeiro: Civilização Brasileira, 2017. 162 p.

BATAILlE, Georges. Documents. Trad. João Camilo Penna e Marcelo Jacques de Moraes. Florianópolis: Cultura e Barbárie, 2018. 272 p.

BÍBLIA SAGRADA. Trad. Antônio Pereira de Figueiredo. São Paulo: Sivadi Editorial, 2010. 1102 p.

DERRIDA, Jacques. O animal que logo sou. Trad. Fábio Landa. São Paulo: Ed. UNESP, 2002.92 p. 
DELEUZE, Gilles; GUATTARI, Félix. Mille Plateaux: Capitalisme et Schizophrénie. Paris: Les Éditions de Minuit, 1980. 641 p.

DELMASCHIO, Andréia; CEI, Vítor. "Literatura Pensante: entrevista com Evando Nascimento". A Palo Seco - Escritos de Filosofia e Literatura, Sergipe, n.9, p.72-77, 2017.

GIORGI, Gabriel. Formas Comuns: animalidade, literatura, biopolítica. Trad. Carlos Nougué. Rio de Janeiro: Rocco, 2016. 238 p.

LISPECTOR, Clarice. A maçã no escuro. Rio de Janeiro: Francisco Alves, 1961. 376 p. MACHADO, Regina Helena de Oliveira. "Crime e desistência nos textos de Clarice Lispector”. Remate de Males, Campinas, v. 9, p. 119-130, 17 jun. 1989.

MACIEL, Maria Esther. "Poéticas do Animal". In: MACIEL, Maria Esther (Org.). Pensar/escrever o animal: ensaios de zoopoética e biopolítica. Florianópolis: Editora da UFSC, 2011, p.85-101.

NASCIMENTO, Evando. Derrida e a Literatura: "notas" de literatura e filosofia nos textos da desconstrução. Niterói: EdUFF, 1999. 363 p.

NASCIMENTO, Evando. "Clarice Lispector: les animaux, les choses, la pensée”. In: BESSE, Marie Graciete; SETTI, Nadia (Org.). Clarice Lispector: une pensée en écriture pour notre temps. Paris: L'Harmattan, 2013, p. 99-117.

NASCIMENTO, Evand o. Clarice Lispector: uma literatura pensante. Rio de Janeiro: Civilização Brasileira, 2012. 303 p.

NASCIMENTO, Evando. Derrida. Rio de Janeiro: Zahar, 2004. 37 p.

NASCIMENTO, Evando. "Eis a defesa da solidariedade dos viventes". Suplemento Cultural do Diário Oficial do Estado de Pernambuco, Recife, n. 138, p.22-23, Ago. 2017.

NIETZSCHE, Friedrich. A Gaia Ciência. Trad. Paulo César de Souza. São Paulo: Companhia das Letras, 2001. 362 p.

NUNES, Benedito. O Mundo de Clarice Lispector (ensaio). Manaus: Edições Governo do Estado do Amazonas, 1966. 77 p.

NUNES, Benedito. O Drama da Linguagem: uma leitura de Clarice Lispector. São Paulo: Ática, 1995. 175 p.

ROSENFELD, Anatol. "Reflexão sobre o romance moderno". In: Texto e Contexto I. 5.ed. São Paulo: Perspectiva, 2009, p. 75-97. 
SÁ, Olga de. Clarice Lispector: a travessia do oposto. 3.ed. São Paulo: Annablume, 2004. 272 p.

WITTGEnSteIn, Ludwig. Tractadus Logico-Philosophieus. Trad. José Arthur Giannotti. São Paulo: Companhia Nacional, 1968. 152 p. 